American Journal of Applied Sciences 1 (3) 160-167, 2004

ISSN 1546-9239

(C) Science Publications, 2004

\title{
Malaysian Service Sectors Adopt FEDI to Boost Exports and Imports
}

\author{
Saravanan Muthaiyah \\ Faculty of Management, Multimedia University, \\ Jalan Multimedia, 63100 Cyberjaya, Selangor, Malaysia
}

\begin{abstract}
Financial Electronic Data Interchange (FEDI) refers to making cash payments electronically rather than utilizing any form of traditional payment methods such as physical checks. The merger of two unique systems namely Electronic Fund Transfer (EFT) and Electronic Data Interchange (EDI) has brought about this new technology. The primary objective of this study is to ascertain how FEDI is currently being implemented by the Royal Customs and Excise department of Malaysia, which is the agency responsible for administrating indirect tax policies in the country. Specifically this study examines the implementation of FEDI, pre and post business processes that were facilitated, transfers of payment received from customs to its various agents and clearance of forms. The study also examines the efficiency of the facilitation and enhancement of business processes due to the implementation of FEDI. This is a classic case of business process reengineering within the department through technology adoption i.e. FEDI.
\end{abstract}

Key words: Electronic Data Interchange, M-Commerce, Inter-Organizational and Intra-Organizational Information Systems

\section{INTRODUCTION}

Both businesses and Governments have realized that the advent of the electronic era has created opportunities along with threats (if the businesses/governments do not react!) within a particular economy. A major force driving knowledge economy is creativity and innovative capability. An example of creativity and innovation is utilization of the Internet for business e.g. Amazon.com uses the Internet to sell books. Governments establishing interactive broadband infrastructure that allows society in general to very quickly download information and communicate using technologies such as teleconferencing, videoconferencing and other Internet and wireless based application is another example. Other aspects of creativity and innovation are digitization, convergence and interactive broadband creation within an economy. Changes within economies as a result of creative and innovative technology are continuously reducing operations cost for government and businesses alike. A survey conducted by the OECD has recently suggested that Internet banking has reduced transaction costs from US $\$ 1.08$ per transaction to US $\$ 0.13$ per transaction.

Inter-organizational and intra-organizational connectivity using computer networks is an important business requirement today ${ }^{[1]}$. This means, an organization must be able to communicate instantly with other organizations to exchange information and to perform business transactions as well as communicate internally between the various business units (e.g., Departments or regional offices) to share and exchange information. Such connectivity is vitally important in today's fast-paced world in order for a business to remain effective, efficient and competitive. This has enabled, to a large extent in recent years increase usage and availability of Information Technology (IT) and the development of the World Wide Web. Companies can share information and hence knowledge more readily ${ }^{[2]}$. It allows them to take a more holistic view of their business processes.

Study objectives and research questions: Financial EDI (FEDI) refers to making cash payment electronically rather than utilizing any form of traditional payment methods such as checks. The primary objective of this study is to ascertain how FEDI is currently being implemented by the royal customs and excise department of Malaysia in collecting tax revenue. Specifically this study examines the previous (pre) and current (post) business processes that facilitate the transfer of tax payments and form clearance made by customs with various agents.

The customs department had previously processed forms in a manual fashion which had resulted in delay of cargo clearance. Each officer would have to sign around 300 forms in a day which takes up many long hours. Since some cargo needs urgent clearance i.e. Perishable goods, the importers bear great losses when this happens.

The study also examines the security or precautionary measures established by Customs while engaging in Financial Electronic Data Interchange (FEDI). Specific research questions that this study aims to address are as follows: 
* To what extent has the implementation of FEDI led towards simplification and non-duplication of work for Customs and its agents?

* To what extent has the implementation of FEDI by Customs led towards wages and stationary cost reduction?

* Does the implementation of FEDI lead to greater transaction volume?

* Has FEDI reduced the idle cash float due to the participating agents?

* Does FEDI provide a platform for enhanced Customer Relation Management (CRM) amongst Customs and their agents?

Electronic Data Interchange (EDI) is an application that emerged in the late 1960's. It is a communications tool that enables companies within a particular industry to exchange a wide range of business documents such as including purchase orders, invoices, bills of lading, shipping orders and confirmations which are manifestations of standard business processes in any business transactions ${ }^{[3]}$.

Over the last two decades, EDI systems have provided a viable means for the utilization of technology to facilitate cross border and interorganizational transactions ${ }^{[4]}$. Most research on EDI however focuses on requirements to ensure these systems works with much emphasis on technical issues such as integrating EDI them into existing applications. Nevertheless the studies which focus on improvements in efficiency and analysis of environmental conditions and success factors for fast and broad technology diffusion.

With the rapid expansion of the Internet, there are a number of initiatives underway for the creation of a secure cost-effective payment system, which will be able to support growing activities in the network ${ }^{[5]}$. Although electronic payment systems to facilitate large payments have been in operation for quite some time, expanding transaction volumes are increasing the pressure for cost-effective and efficient electronic payment systems. A number of factors, including drastically reduced costs of computing hardware, software and telecommunications combined with the lifting of trade barriers across Europe mean that EDI is moving from an embryo, innovative phase into a phase of exponential global growth.

Another major factor is the increasing realization of the role of EDI as a business enabler to increase competitive and dynamic markets ${ }^{[6]}$. EDI can be conceptualized as a member of a family of technologies for communicating business messages electronically, including facsimile (fax), electronic mail, telex and computer conferencing systems (bulletin boards). Businesses use each of these technologies to exchange commercial messages with their respective trading partners. The boundaries between these technologies are not rigid. A message may, for example, begin as an
EDI message, but later be converted (by perhaps an intervening network provider) into fax or e-mail format before its ultimate delivery.

As electronic commerce is envisioned to become the way to do business in all industries ${ }^{[7]}$ Financial Electronic Data Interchange (FEDI) and other forms of electronic commerce are speeding transactions, improving customer service and reducing costs for companies of all sizes. Corporations, government agencies and entire industry segments are expected to demand a full range of financial EDI services. Providing these services would be essential for organizations that intend to retain and grow within the domain of payments and cash-management business.

EDI is commonly defined as the application-to application transfer of business documents between computers. Many businesses choose EDI as a fast, inexpensive and safe method of sending purchase orders, invoices, shipping notices and other frequently used business documents. Nevertheless EDI is quite different from sending electronic mail messages or sharing files through a network, a modem, or a bulletin board. The straight transfer of computer files requires that the computer applications of both the sender and receiver (referred to as "trading partners") agreeing upon a predetermined format of the document. The sender must use an application that creates a file format identical to that of the receiver.

FEDI benefits: Initial EDI applications have concentrated on corporate efficiency by improving data flow and error reduction. In these instances the business case for EDI was based primarily on direct cost savings. Genentech, Inc. - A leading pharmaceutical manufacturer and biotechnology research firm based in San Francisco-continually seeks faster, more economical and more efficient ways to get its products into the hands of customers. Genentech's sales and marketing department determined that improved customer service and reduced costs could be achieved by introducing EDI technologies into the sales order cycle.

Today Genentech is reaping the many rewards of an integrated EC implementation that includes several custom-built EDI tools. Benefits include amongst others, significant reduction in data-entry errors and faster product shipped to the manufacturer's customers. The most noticeable benefit has been the reduction of time required to process orders. At the end of their first year of EDI purchase orders, the order department expects to realize savings equivalent to the salary of one full-time staff member. Electronic commerce and EDI are assisting Genentech to save money, while offering it with the ability to enhance customer relationship management.

In addition to reducing direct cost, EDI also has the ability to increase labor efficiency. A study on Kessler Industries Incorporated, a family-owned manufacturer 
of metal indoor and outdoor furniture is a case in point. In the early 1990s, Kessler began doing business electronically with a large retailer and as more customers became interested in EDI, the company sought to expand and integrate its electronic commerce initiative. In order to create a link between EDI and their manufacturing system, the company utilized EDI translation and integration software to link EDI to its internal applications and to create customized templates for documents such as purchase orders, invoices, advance ship notices and price/sales catalogs. The benefits of Kessler's integrated EDI system include improved customer service and customer satisfaction, labor savings and improved accuracy.

Utilization of EDI to transmit invoices data and payments can improve a company's cash flow management while increasing the amount of working capital, achieved via efficient account handling. A case in point is ShopNet Singapore, an industry-wide integrated Information Technology (IT) community developed jointly by the Singapore Article Number Council, the Retail Promotion Centre and the National Computer Board for small retailers in housing estates. Shop Net empowers small retailers in Singapore to conduct Point-of-Sales (POS) scanning, inventory control and EDI for procurement purposes. Currently, there are 170 retailers and 38 major suppliers participating in the ShopNET project. Benefits cited by retailers participating in the project include:

* Access to vital product information from suppliers

* Store specific product mix for better customer service

* Standardization of product code and symbols

* Electronic tracking of product movement at each store

* improved cash flow through increase in stock turnover and reduction of inventory

* Daily electronic sales and profit reporting on a store by store basis

Hypotheses 1 to 3 are interrelated. Hypothesis 1 which states that the implementation of FEDI will reduce the workload as manual work can be reduced via fully computerized systems which simplifies business processes while reducing non-duplication of work.

Hypotheses 4 and 5, suggest that the implementation of FEDI enhances effectiveness and efficiency of business processes and this in turn leads to a reduction of the idle cash float payments due to participating agencies. In summary, from the perspective of the Royal Customs and Excise Department of Malaysia, their agents and based on contemporary review of literature, the implementation of the financial EDI would include increasing the speed of posting of funds through increased automation and processing accuracy. Technically there was seriously in the requirement for FEDI to be implemented in the case of customs.
Failing to adopt would mean that importers and exporters would prefer to use Singapore as a gateway to bring in goods into Malaysia. Royal Customs and Excise Department of Malaysia now has a business risk. If the goods are brought into Singapore simply because the Malaysian enforcement agency wasn't equipped with the technology for speedy delivery than a huge amount of tax revenue will be lost. The manual systems or legacy systems were just too slow an expensive.

\section{MATERIALS AND METHODS}

This is an exploratory research, where not much is known about the situation at hand and information is scarce on research issues that had been resolved previously. Thus, the main reason of this research was to generate more knowledge and improve understanding of the FEDI concept and its impact on the Customs department. We wanted to see the effect of automation of processes on the scalability on form processing specifically Form 1 (Customs Import), Form 2 (Customs Export) and Form 8 (Transshipment).

The research is based on qualitative approach that relates to a test or measurement, which determines the usefulness of Financial Electronic Data Interchange. This is within the FTZ geographic area in Malaysia with special focus on the island of Penang, the nation's hub for import and exports. The FTZ zone in Penang includes the Penang International airport in Bayan Lepas, the seaport and Penang Free Trade Zone. The focus of the research is to determine the movement of forms between Free Trade Zone and Bayan Lepas International airport.

For the purpose of this study, information was gathered through primary and secondary sources. To achieve a more reliable outcome, questionnaires were sent through mail to all the agents and customs personnel in the following Free Trade Zones i.e. Penang, Sungei Way, KLIA, Johor and Butterworth. Our main focus was on those that have already adopted FEDI.

This offers the potential of reducing commission levied to participating agencies. These factors will provide a higher satisfaction to participating agencies as they can receive payment earlier. This reduces the opportunity cost of late payment for agencies participating within a FEDI environment. These are prerequisites for providing a platform for superior Customer Relation Management for banks.

\section{RESULTS AND DISCUSSION}

A total of 500 questionnaires was sent by post, email, fax, in addition to personal interviews with agents and customs officers in Kuala Lumpur, Sungei Way, Penang (sea port), Penang (airport), logistics providers, freight forwarding agents, cargo operators and warehousing personnel. 
Table 1: Summarizes key hypotheses that were formulated to facilitate this study

Hypothesis 1

Implementation of FEDI reduces workload, simplification and non-duplication of business processes

Hypothesis 2

Implementation of FEDI systems will reduce wages and stationery cost

Hypothesis 3

Hypothesis 4

Hypothesis 5

Fill increase the number of transaction volume

Implementation of FEDI systems will increase the tax revenue of the government

Implementation of FEDI systems increases competitive advantage for an institution as a

result of reduction in commissions charged levied to participating agents

Hypothesis 6

The implementation of FEDI will provide a platform for effective Customer Relation

Management solutions

Table 2: Antecedents of FEDI Implementation

\begin{tabular}{llll} 
& & Aggregate \\
Performance Evaluation & Contributing Factors & N & $\%$ \\
\hline Most important & Advancement in computer technology & 1017 & 28.18 \\
$2^{\text {nd }}$ important & Transaction volume increases & 791 & 21.92 \\
$3^{\text {rd }}$ important & Security of the electronic payment system & 687 & 19.06 \\
$4^{\text {th }}$ important & Competition & 467 & 12.94 \\
$5^{\text {th }}$ important & Reduce processing/ human error & 363 & 10.66 \\
Least important & Others & 284 & 7.87 \\
& & 3609 & 100 \\
\hline
\end{tabular}

Table 3: Problems in the Implementation Process

\begin{tabular}{llll}
\hline $\begin{array}{l}\text { Performance } \\
\text { Evaluation }\end{array}$ & Problems & Aggregate \\
\hline Most important & $\begin{array}{l}\text { Management } \\
\text { support }\end{array}$ & 534 & $\%$ \\
\hline $\begin{array}{l}\text { 2ime consuming } \\
2^{\text {nd }} \text { important }\end{array}$ & 391 & 24 \\
$3^{\text {Td }}$ important & $\begin{array}{l}\text { Agencies } \\
\text { reluctance to } \\
\text { change to new }\end{array}$ & & \\
& system & & \\
& 35421.7 & 351 & 21.5 \\
4th important & Cost involve & 1630 & 100 \\
\hline
\end{tabular}

Respondents were predominantly from this group of people who were actually our focus group. Out of this, only 219 respondents really answered the questionnaire completely and correctly the other questionnaires were spoilt thus giving this study a response rate of $43.8 \%$.

Findings on FEDI implementation: An estimated $70 \%$ of the respondents namely logistics providers freight forwarding agents, cargo operators and warehousing personnel had implemented the system more than 5 years ago:

\begin{tabular}{llllll}
\hline & & & & Valid & Cumulative \\
& & Frequency & $\%$ & $\%$ & $\%$ \\
\hline Valid & $1-3$ years & 15 & 6.84 & 7.04 & 7.04 \\
& 3-5 years & 48 & 21.92 & 22.72 & 29.76 \\
& $>5$ years & 150 & 68.49 & 70.24 & 100.0 \\
& Total & 213 & 97.3 & 100.0 & \\
Missing & 9 & 6 & 2.71 & & \\
\hline Total & & 219 & 100.0 & & \\
\hline
\end{tabular}

Antecedents of FEDI implementation: Respondents were asked to rank the factors that led to the implementation of FEDI systems. Specific reasons include advancement in computer technology, competition, transaction volume increased, reduced processing and human error, security of the electronic payment system and others. Table 2 shows the overall ranking of the reasons that contributed to the implementation of FEDI. The most important factor was assigned 6 points, followed by $2^{\text {nd }}$ most important value with 5 points and so on. Total points for all respondents were obtained and were ranked as follows.

Problems during implementation: The Table 3 shows the overall ranking of the problem faced in implementing the system. The most important is assigned 4 points, followed by $2^{\text {nd }}$ most important value with 3 points and so on. Total points for all respondents are totaled to determine an overall ranking.

Hypothesis 1: Implementation of FEDI reduces workload, simplification and non-duplication of business processes. On this hypothesis, the objective is to find out whether the implementation of FEDI has reduced the workload of employees compared to the manual system used for the receipt of payments to the reconciliation of information to the various agencies. The questions that were developed to support the hypothesis are:

Do you think the FEDI is able to simplify the payment system?

\begin{tabular}{llll}
\hline & Frequency & Percent & \\
\hline Valid & Yes & 219 & 100.0 \\
\hline
\end{tabular}

Do you think the FEDI reduces work duplication of the payment system?

\begin{tabular}{llll} 
& & Frequency & Percent \\
\hline Valid & Yes & 219 & 100.0
\end{tabular}


Did implementation of this system have an effect upon the payment workload in any way?

\begin{tabular}{llll}
\hline & & Frequency & Percent \\
\hline Valid & Yes & 150 & 68.5 \\
& No & 36 & 16.44 \\
& Total & 218 & 99.54 \\
Missing & 9 & 1 & 0.46 \\
\hline Total & & 219 & 100.0 \\
\hline
\end{tabular}

All the 219 respondents agree that the FEDI system is able to simplify and reduce work duplication of the payment system. However, $31.5 \%$ respondents disagree that the system has an effect upon the payment workload. According to them, the payment workload has no significant changes although the payment system is simplified and non-duplicated with the implementation of FEDI system. But in overall result, $68.5 \%$ agree that the implementation of FEDI system reduces the payment workload. In this context, the hypothesis can be generally accepted.

Hypothesis 2: Implementation of FEDI systems will reduce wages and stationery cost this hypothesis is only relevant to the managerial level where they have knowledge on vital financial information within a firm. One respondent from Customs says that the use of FEDI offers an important cutting-edge benefit to customers to help them compete in today's market. But even the best technology needs the 'human element' to ensure success.

Therefore, it is said that while there could be elimination of staff within the existing departments, recruitment of staff in the IT Department, customer relationship and database administration will still be required. The second part of the hypothesis test on whether stationery cost such as the paper, pen and space for storage of documents are reduced via the implementation of the FEDI system. Specifically, the following issues were addressed:

Did implementation of this system have an effect upon stationery costs in any way?

\begin{tabular}{llllll}
\hline & & & & Valid & Cumulative \\
& & Frequency & Percent & Percent & Percent \\
\hline Valid & Yes & 86 & 39.3 & 47.1 & 47.1 \\
& No & 80 & 36.53 & 52.9 & 100.0 \\
& Total & 166 & 75.80 & 100.0 & \\
Missing & 9 & 53 & 24.2 & & \\
\hline Total & & 219 & 100.0 & & \\
\hline
\end{tabular}

Did implementation of FEDI have an effect upon wage costs in any way?

\begin{tabular}{llll}
\hline & & Frequency & Percent \\
\hline Valid & Yes & 160 & 73.06 \\
Missing & 9 & 59 & 26.94 \\
\hline Total & & 219 & 100.0 \\
\hline
\end{tabular}

$52.9 \%$ of the respondents disagreed that the FEDI system has an effect upon wage costs. According to them, though the employees handling the manual work decreases, but the need for IT staff to operate the system increases at the same time. Thus the effect upon wage costs was not significant. $75.8 \%$ of the respondents agree that the system decreases the stationary costs.

Hypothesis 3: FEDI will increase the number of transaction volume.

As technology advancement is evolving rapidly, companies are under more pressure than ever to operate efficiently and cost-effectively. The quickest way to reduce errors and increase competitive edge is through electronic trading communities. Therefore the Financial Electronic Data Interchange (FEDI) is seen as a method of helping businesses to meet this requirement ${ }^{[8]}$.

This hypothesis aims to test whether firms using FEDI are more efficient in terms of processing volume of transactions compared to the traditional manual techniques. The Table below suggests that $84.6 \%$ of the respondents agree that the FEDI system increases the number of transaction volume. Therefore, this hypothesis should be accepted:

\begin{tabular}{llllll}
\hline & & Frequency & $\%$ & Valid \% & Cumulative \% \\
\hline Valid & Yes & 178 & 81.28 & 84.6 & 84.6 \\
& No & 38 & 17.35 & 15.4 & 100.0 \\
& Total & 216 & 98.63 & 100.0 & \\
Missing & 9 & 3 & 1.4 & & \\
\hline Total & & 219 & 100.0 & & \\
\hline
\end{tabular}

Hypothesis 4: Implementation of FEDI systems will increase the tax revenue of the government.

By combining the speed and convenience of technology with highly personalized service, the implementation of FEDI helps process transactions more efficiently, thus optimizing the agencies' cash flow and improve their bottom line. Factors that can lead to increase in revenue for the government (Customs) that have implemented FEDI systems is the improvement in fund availability of agencies as paperless transactions increases the speed the posting of funds through the increased automation and improved processing accuracy. This thus creates a strategic partnership between the agencies and the collection intermediaries that will enable the firm to reach out to a larger market. Prior to the implementation of FEDI systems, $100 \%$ of the respondent bank-in the payment of the participating agencies' accounts. Hypothesis 4 can be stated in the null and alternate as follows:

$\mathrm{H} 1_{\mathrm{O}}$ : There will be no difference in the tax revenue before and after the implementation of FEDI 
system. Statistically expressed: $\mathrm{H} 1_{\mathrm{O}}$ is $\mu_{\mathrm{b}}=\mu_{\mathrm{a}}$. Where $\mu_{\mathrm{b}}$ is tax revenue before the implementation and $\mu_{\mathrm{a}}$ is tax revenue after the implementation.

$\mathrm{H} 1_{\mathrm{A}}$ : The FEDI system will increase the tax revenue. Statistically expressed: $\mathrm{H} 1_{\mathrm{A}}$ is $\mu_{\mathrm{a}}>\mu_{\mathrm{b}}$ or $\mu_{\mathrm{b}}<\mu_{\mathrm{a}}$

A t-test was done to see if there are any significant differences in the means of two groups in the variable of interest. That is, a nominal variable that is split into two subgroups (in this case, before and after the implementation of FEDI is tested to see if there is a significant mean difference between the two split groups. The $t$-test takes into consideration the means and standard deviations of the two groups on the variable and tests whether the numerical difference in the mean is significantly different from 0 (zero) as postulated in the null hypothesis.
A t-test will indicate if the implementation of FEDI system has an effect on the tax revenue collected. The result of the t-test done is shown in the Tables below. As can be seen, the difference in the means of 3.31 and 1.7 with a standard deviation of 1.22 and 0.56 for before and after implementation is significant. The null hypothesis is rejected as the $t$ value falls outside of the region. The means of 3.31 and 1.7 for before and after implementation of the FEDI system indicate that tax revenue collection reduced from 4-5 days to 1-3 days. Please refer to the scales below for the speed of processing. Therefore, it supports the alternate hypothesis that the FEDI system reduces the idle cash float, $\mu_{\mathrm{a}}>\mu_{\mathrm{b}}$.

\section{Scales:}

$1=<1 \quad 2=1-3 \quad 3=4-5 \quad 4=6-7 \quad 5=>1$

Day days days days week

\section{Paired sample statistics}

\begin{tabular}{|c|c|c|c|c|c|}
\hline & & Mean & $\mathrm{N}$ & Std.Deviation & Std.Error Mean \\
\hline \multirow{4}{*}{$\begin{array}{l}\text { Pair } \\
1\end{array}$} & Before the implementation of FEDI what was the & & & & \\
\hline & lead time for a form to be processed and cargo & & & & \\
\hline & cleared? & 3.31 & 219 & 1.222 & .096 \\
\hline & $\begin{array}{l}\text { After the implementation of FEDI what was the } \\
\text { Lead time for a form to be processed and cargo } \\
\text { cleared? }\end{array}$ & 1.70 & 219 & 0.558 & .044 \\
\hline
\end{tabular}

Paired sample test

\begin{tabular}{|c|c|c|c|c|c|c|c|c|}
\hline & \multicolumn{2}{|c|}{ Paired Differences } & \multicolumn{6}{|l|}{ Std. } \\
\hline & $\begin{array}{l}\text { Std. } \\
\text { Mean }\end{array}$ & $\begin{array}{l}\text { Error } \\
\text { Dev. }\end{array}$ & $\begin{array}{l}\text { Difference } \\
\text { Mean }\end{array}$ & $\begin{array}{l}95 \% \text { Interval } \\
\text { of the Lower }\end{array}$ & $\begin{array}{l}\text { Confidence } \\
\text { Upper }\end{array}$ & $\mathrm{t}$ & $\mathrm{df}$ & $\begin{array}{l}\text { Sig. } \\
\text { (2-tailed) }\end{array}$ \\
\hline $\begin{array}{l}\text { Pair } 1 \text { Before and After } \\
\text { the implementation } \\
\text { of FEDI }\end{array}$ & 1.61 & 0.851 & 0.067 & 1.48 & 1.74 & 24.106 & 219 & 0.000 \\
\hline
\end{tabular}

Hypothesis 5: Implementation of FEDI systems increases competitive advantage for the institution as a result of reduction in commissions charged levied to participating agents.

Here the hypothesis aims to test whether commissions can be reduced as a result of lower transaction cost incurred such as call volumes and payment-processing cost due to the implementation of the financial EDI system. One of the characteristics faced by these intermediary collectors in the competitive environment is the 'kinked demand' curve like in an Oligopoly economic system whereby if the firm tries to raise its commission, other firms will not follow and thus it will lose more of its sales. In this form of informal collusive behavior, the price or commission rate charged tends to be sticky because if a firm reduces the commission, most of the firm will immediately try and follow suit.

$92.6 \%$ of the respondents agree that the FEDI system has an effect upon participating agencies' cost.
Further analysis reveals that $95 \%$ of the respondents believe that this will lead to a competitive advantage for both banks and participating agencies. Based on the respondents' answer, this hypothesis can be accepted.

Hypothesis 6: The implementation of FEDI will provide a platform for effective Customer Relation Management solutions.

Customer relationship management specializes in selected industries in order to understand the needs, trends and special requirements of the customers in the segments they serve. One respondent says that by having a financial EDI system, the service sector namely the government is able to deliver value-added solutions to agents that will enable them to more effectively service their staff, while satisfying government regulatory requirements. There are a number of other objectives that can be achieved by the FEDI.

These would include: 
- Form processing performed by Customs

- Manifest checking and processing

- Billing and payment processing

- Facilities movement to JIT purchasing, if desired
- Implement EDI invoicing with manifest matching

- Eliminate the need for staff increases

- Lower cost method of doing business

- High agent satisfaction

Did the implementation of the system have an effect upon participating agencies' cost in any way?

\begin{tabular}{|c|c|c|c|c|c|}
\hline \multirow{2}{*}{$\overline{\text { Valid }}$} & & Frequency & Percent & Valid Percent & \\
\hline & Yes & 198 & 90.4 & 92.6 & Cumulative Percent \\
\hline & No & 20 & 9.13 & 7.4 & \multirow[t]{2}{*}{100} \\
\hline & Total & 218 & 99.54 & 100 & \\
\hline Missing & 9 & 1 & 0.46 & & \\
\hline \multicolumn{2}{|l|}{ Total } & 219 & 100 & & \\
\hline \multirow{2}{*}{\multicolumn{2}{|c|}{$\begin{array}{l}\text { Performance } \\
\text { Evaluation }\end{array}$}} & & & \multicolumn{2}{|l|}{ Aggregate } \\
\hline & & \multicolumn{2}{|l|}{ Expectations } & $\mathrm{n}$ & $\%$ \\
\hline \multicolumn{2}{|c|}{ Most preferred } & \multicolumn{2}{|l|}{ Happy agents } & 1311 & $21.42 \%$ \\
\hline \multicolumn{2}{|c|}{$2^{\text {nd }}$ preference } & \multicolumn{2}{|c|}{ Lower cost secure way of doing business and } & 993 & $16.23 \%$ \\
\hline \multirow{2}{*}{\multicolumn{2}{|c|}{$3^{\text {rd }}$ preference }} & \multicolumn{2}{|c|}{ Implement EDI invoicing with PO matching; } & 803 & $13.12 \%$ \\
\hline & & Manifest checking ar & $\operatorname{sing}$ & 773 & $12.63 \%$ \\
\hline \multicolumn{2}{|c|}{$5^{\text {th }}$ preference } & \multicolumn{2}{|c|}{ Eliminate the need for staff increases; } & 659 & $10.77 \%$ \\
\hline \multicolumn{2}{|c|}{$6^{\text {th }}$ preference } & \multicolumn{2}{|c|}{ Form processing performed by Customs; } & 628 & $10.26 \%$ \\
\hline \multicolumn{2}{|c|}{$7^{\text {th }}$ preference } & \multirow{2}{*}{\multicolumn{2}{|c|}{$\begin{array}{l}\text { Facilities movement to JIT purchasing, if desired; } \\
\text { Billing and payment processing }\end{array}$}} & 603 & $9.85 \%$ \\
\hline \multirow{2}{*}{\multicolumn{2}{|c|}{ Least preferred }} & & & 350 & $5.72 \%$ \\
\hline & & \multicolumn{2}{|c|}{ Billing and payment processing } & 6120 & $100 \%$ \\
\hline
\end{tabular}

The table above shows the overall ranking for each of the expectation to be achieved by the implementation of FEDI system. The most important outcome was assigned 8 points, followed by $2^{\text {nd }}$ most important value with 7 points and so on. Total points for all respondents are totaled to determine an overall ranking.

Based on the above, we can suggest that the most preferred expectation of FEDI implementation is to improve Customers Relationship Management (CRM). This is supported by their frequent revision of customer service policies within agencies and the Customs. 38\% of the respondents update their customer service policy every year. 33\% will have a formal policy update constantly based upon client's needs and $27 \%$ have rewritten the policy within last 2 years. That means $98 \%$ of the respondents will revise their policy every two years. This implies that Customer Relationship Management (CRM) is of great importance to them in managing and making decisions. In addition, $77 \%$ of the respondents believe that the FEDI system can provide a platform for CRM. According to them, they enjoy a high degree of customer loyalty based upon the current service provided. Rarely there is any formal complaint from end-users or agencies related to the system.

\section{CONCLUSION}

In summary FEDI implementation can be described as a value-added service, which can enhance service delivery for Malaysian Customs and participating agencies through network optimization, collaboration services and consulting. This helps trading partners, or in this case the agencies involved, to take full advantage of the system, managing the change efficiently, strengthening relationships and discover totally new ways of doing business. The use of financial EDI also improves customer service as the related agencies can access their account information on a 24-hour basis as all payments made are typically applied directly to the agencies' account on the next business day based on individual client billing. This enables customers to receive the level of control they desire, with new levels of convenience and flexibility that make it easier for them to check payment updates and all related information 24 hours a day, seven days a week, 365 days in a year.

\section{REFERENCES}

1. The New York Times, 2000. Almanac, s.v. Primetime Viewing Shares of Free and Cable TV Networks, 1995-98, p. 408.

2. Kalakota, R. and M. Robinson, 1999. EBusiness: Roadmap for Success. Reading, M.A: AddisonWesley.

3. Kalakota, R. and A. Whitson, 1996. Readings in ECommerce. Reading, M.A: Addison-Wesley.

4. Jeffery, F. Rayport and Bernard J. Jaworski, 2001. Readings in E-Commerce, M. A: McGraw Hill.

5. Brands S., 1994. A Proposal for an Internet Cash System, CWI. 
6. Farhoomand, A. F. and E. Pace, 1995. An Exploratory Investigation of Electronic Commerce Use in International Trade. In Proceedings of the 3rd European Conference on Information Systems, 33-41, Eds. G. Doukidis, B. Galliers, T. Jelassi, H. Kremar and F. Land, Athens, Greece.
7. Castells, M., 1996. The Rise of the Network Society. Cambridge, M. A: Blackwell.

8. Financial Electronic Data Interchange Status, 2001. [Online], Available: http://www.uboc.com/ 